\section{Gunnar Németh}

Received: 17 October 2005

Accepted: 23 October 2005

Published online: 1 December 2005

(C) Springer-Verlag 2005

\section{G. Németh}

Capio AB, Gothenburg, Sweden

E-mail: gunnar.nemeth@capio.com

Tel.: + 46-31-7324000

Fax: + 46-31-7378799

G. Németh

Karolinska Institutet, Stockholm, Sweden

\section{Health related quality of life outcome instruments}

might be used for calculating quality-adjusted life-years.

Keywords Health status Health status indicators · Quality of life · Quality-adjusted life-years · Questionnaires/ standards $\cdot$ Review $\cdot$ SF-36 . Nottingham Health Profile Sickness Impact Profile · EuroQol $\cdot$ EQ-5D $\cdot$ SF-6D

\section{Introduction}

Health is the most significant part of quality of life. Generally, quality of life outcome instruments used in healthcare confine their attention to health related areas, assessing health related quality of life (HRQoL). Commonly assessed areas are (a) physical function, (b) psychological well-being, (c) subjective symptoms, (d) social function and (e) cognitive function. Outcome from HRQoL instruments reflects patient's own experience of gained (or lost) HRQoL and provides a non-disease specific outcome measure. There has been a relative scarcity of such studies in journals dealing with spinal diseases. Three reviews from 2000 describes the literature [17, 45, 79].

The purpose of the present paper is to describe some commonly used health profile instruments [25] such as the generic measures SF-36, Nottingham
Health Profile (NHP) and Sickness Impact Profile (SIP); and the preference-based measures EuroQol and SF-6D.

\section{Generic health profile instruments}

\section{SF-36}

The Medical Outcomes Trust short form questionnaire with 36 questions, most often referred to as SF-36 ${ }^{1}$, is a measure of general health status relevant across age, disease and treatment groups, widely used and tested in a range of conditions and settings, including spine re-

\footnotetext{
${ }^{1}$ An SF-36 licence can be obtained at http://www.sf-36.org (accessed 2 October 2005) and a reference kit can be ordered at http:// www.qualitymetric.com/products/ProductDetails.aspx?ProductID $=468 \&$ categoryid $=1$ (accessed 2 October 2005)
} 
search, e.g. $[17,25,57,58,72,73]$. It is available in a number of languages. ${ }^{2}$

In 1991, the International Quality of Life Assessment launched a project aiming at translating, validating and norming the SF-36 health survey. The SF-36 was published in 1992 by Ware and Sherbourne, and further developed and validated in 1993 and 1994, respectively $[47,48,74]$. It is self- or interviewer-administered and a computerised administration is also available. The form takes about 5-10 min to complete. In general, SF-36 has been shown to be acceptable to people with disabilities [1]. Some changes in wording was suggested for respondents using wheelchairs, for example due to spinal cord injury [49].

The items in SF-36 are divided into eight different domains with overall physical and mental health component summary scores. Domains are physical functioning, role limitations physical, bodily pain, social functioning, general mental health, role limitations emotional, vitality and general health (Table 1). One advantage with SF-36 is the existence of normative data and its documented reliability and validity, e.g. [17].

Since several years, the SF-36 is used for assessments in the Swedish national register for lumbar spine surgery $[64,65]$. It has been shown to be useful in describing different diagnostic profiles in persons operated on for lumbar spine disorders [78]. Further it is responsive to changes in outcome in patients operated on and useful in comparing outcome in spine surgery across nations [78]. As described later in the current article, a preferencebased score, SF-6D has been developed allowing gained HRQoL to be calculated.

\footnotetext{
${ }^{2}$ SF-36 is currently available in Afrikaans, Armenian, Bulgarian, Chinese for Hong Kong, Chinese for Singapore, Chinese for Taiwan, Chinese for the USA, Croatian, Czech, Danish, Dutch, Dutch for Belgium, English for Australia, English for Canada, English for Hong Kong, English for Malaysia, English for New Zealand, English for the Philippines, English for Singapore, English for South Africa, English for Taiwan, English for the UK, Estonian, Finnish, French, French for Belgium, French for Canada, French for Switzerland, German, German for Austria, German for Switzerland, Greek, Gujarati, Hebrew, Hungarian, Icelandic, Iranian, Italian, Italian for Switzerland, Japanese, Japanese for the USA, Kiswahili, Korean, Latvian, Lithuanian, Malay for Malaysia, Malay for Singapore, Malayalam, Marathi, Norwegian, Polish, Portuguese, Portuguese for Brazil, Romanian, Russian, Serbian, Slovak, Slovenian, Spanish, Spanish for Argentina, Spanish for Chile, Spanish for Colombia, Spanish for Costa Rica, Spanish for Guatemala, Spanish for Honduras, Spanish for Mexico, Spanish for Peru, Spanish for Puerto Rico, Spanish for the USA, Spanish for Uruguay, Spanish for Venezuela, Swedish, Tagalog, Telugu, Thai, Turkish, Ukrainian and Vietnamese for the USA. Source: http://www.proqolid.org/, accessed 2 October 2005.
}

SF-12

SF-12 was developed as an abbreviated version of the SF-36 for use in large surveys of general and specific populations as well as large longitudinal studies of health outcomes. ${ }^{3}$ It was developed by Ware et al. and published in 1996 [75] including data on reliability and validity. It can be obtained from the SF Community. ${ }^{4}$ Possible administration includes self-, interview-, telephone- or computer-administered recording. SF-12 takes 5 min or less to complete.

\section{Sickness Impact Profile}

Sickness Impact Profile ${ }^{5}$ was first published in 1976 and a revised version was published by Bergner et al. in 1981 [2]. It is intended for self-administration or interview and contains 136 items. SIP takes $20-30$ min to complete and is available in several languages. ${ }^{6}$ There are two domains, physical and psychosocial, containing 12 categories (Table 1). The physical domain contains ambulation, mobility, body care and movement. Psychosocial domain contains social interaction, communication, alertness behaviour, emotional behaviour, sleep and rest, eating, home management, recreation and pastimes and employment. Scoring may be done on domain or category levels as well as at the total SIP level.

\footnotetext{
${ }^{3}$ SF-12 is currently available in Afrikaans, Bulgarian, Chinese for Hong Kong, Chinese for Singapore, Chinese for Taiwan, Croatian, Czech, Danish, Dutch, Dutch for Belgium, English for Australia, English for Canada, English for Hong Kong, English for India, English for New Zealand, English for South Africa, English for Taiwan, English for the UK, Estonian, Finnish, French, French for Belgium, French for Canada, French for Switzerland, German, German for Austria, German for Switzerland, Greek, Gujarati, Hebrew, Hindi, Hungarian, Italian, Italian for Switzerland, Japanese, Kannada, Korean, Latvian, Lithuanian, Malay for Malaysia, Malay for Singapore, Malayalam, Marathi, Norwegian, Polish, Portuguese, Portuguese for Brazil, Romanian, Russian, Slovak, Slovenian, Spanish, Spanish for Argentina, Spanish for Chile, Spanish for Mexico, Spanish for Puerto Rico, Spanish for the USA, Swedish, Tagalog, Telugu, Thai, Turkish, Ukrainian, Xhosa and Zulu. Source: http://www.proqolid.org/, accessed 2 October 2005.

${ }^{4}$ http://www.sf-36.org/tools/sf12.shtml, accessed 2 October 2005.

5 The instrument can be ordered from Medical Outcomes Trust, a not for profit organisation, at http://www.outcomes-trust.org/ instruments/SIPpack.htm (accessed 25 September 2005). The package includes a copy of the instrument including royalty-free permission to use and reproduce and user manual.

${ }^{6}$ Sickness Impact Profile is currently available in Arabic, Chinese for Hong-Kong, Danish, Dutch, Dutch for Belgium, English for Mexico, English for the UK, Finnish, French, French for Belgium, German, Italian, Norwegian, Portuguese, Russian, Spanish, Spanish for Mexico, Spanish for the USA (Chicano Spanish for the Southwest USA), Swedish, Tamil and Thai. Source: http:// www.proqolid.org/, accessed 2 October 2005.
} 
Table 1 Domains and/or categories for three generic health profile instruments

\begin{tabular}{lll}
\hline SF-36 & Nottingham Health Profile & Sickness impact profile \\
\hline Physical functioning & Physical mobility & Physical \\
Role limitations due to physical problems & Pain & Ambulation \\
Bodily pain & Social isolation & Mobility \\
General health perceptions & Emotional reactions & Body care \\
Vitality & Energy & Movement \\
Social functioning & Sleep & Psychosocial \\
Role limitations due to emotional problems & & Social interaction \\
Mental health & & Communication \\
Health transition & & Alertness behaviour \\
& & Emotional behaviour \\
& & Independent \\
& & Sleep and rest \\
& & Eating \\
& & Home management \\
& Recreation \\
& & Employment
\end{tabular}

The SIP is a reliable and valid instrument [17, 45], it has been used in several spine studies such as cervical disc hernia and neck pain [32, 44, 52, 54], lumbar disc herniation, spinal stenosis and back pain [41, 43, 56, 66], vertebral deformities and osteoporosis [24, 53], chronic pain and spinal cord stimulation [9, 51, 63, 77], ankylosing spondylitis $[33,34]$ and in evaluation of iliac crest donor problems [29].

\section{Nottingham Health Profile}

Nottingham Health Profile ${ }^{7}$ was developed by Hunt et al. and published in 1981 [35]. It is intended for selfadministration and contains 38 items in six sections and takes about $10 \mathrm{~min}$ to complete, it is available in different languages ${ }^{8}$ and can be self- or intervieweradministrated. Sections or categories are physical mobility, pain, social isolation, emotional reactions, energy and sleep (Table 1). Each item is weighted and dimensions scores range from 0 to 100 . Mean score is calculated across all items. The NHP was designed to reflect a lay perception of health status as opposed to the professional perception.

Use of the NHP in musculo-skeletal research includes for example studies on osteoporosis [18, 23, 68],

\footnotetext{
7 Address for contact: Dr. Stephen McKenna, Director of Research, Galen Research, Enterprise House, Manchester Science Park, Lloyd Street North, Manchester M15 6SE, UK. Tel.: + 44161-2264446; Fax: +44-161-2264478; E-mail: smckenna@galenresearch.com. Source: http://www.blackwell-synergy.com/doi/full/ 10.1111/j.1524-4733.2004.7s110.x, accessed 4 October 2005.

${ }^{8}$ Nottingham Health Profile is currently available in Arabic, Danish, Dutch, English for the USA, Finnish, French, German, Greek, Hungarian, Italian, Japanese, Norwegian, Portuguese for Brazil, Spanish and Swedish. Source: http://www.proqolid.org/, accessed 2 October 2005.
}

vertebroplasty [19, 42], sciatica [40], low back fusions [60] and other musculo-skeletal disorders [15].

\section{Preference-based health profile instruments}

Preference-based HRQoL instruments are increasingly used in outcome studies. The recorded values or ratings are obtained from patients themselves. Values or indexes are commonly between 0 (death) and 1 (full health). There are different techniques to obtain indexes based on a group's estimate of differences in perceived health status. Time Trade-off is used in EuroQol [20, 21]. Values for SF-6D have been obtained with both Standard Gamble and Visual Analogue Scale (VAS) $[4,5]$. Tosteson published an excellent review in 2000 [69].

Data from preference-based HRQoL outcome instruments are used for calculating QALYs (qualityadjusted life-years), which is needed in the analysis of monetary aspects of different interventions, e.g. [31]. The denominator in cost-benefit analysis is usually a monetary unit, for example Euros - the effect or consequence of an intervention is expressed in cost for intervention per Euro benefit. There might be reservations to value benefits in monetary units; some would instead prefer to use a preference-based utility measure such as gained HRQoL. If increased HRQoL is assessed and multiplied with the length of time affected, one can express this generic outcome in gained QALYs (Fig. 1). For example, a 64-year-old female patient is operated on for a lumbar spinal stenosis. Her HRQoL increases from 0.45 preoperatively to 0.8 postoperatively (K. A. Jansson et al., submitted for publication), a gain of 0.35 . The expected survival time is 10 years. Thus the gain in QALY is $0.35 \times 10=3.5$ QALYs. The calculated cost per gained QALY is often used in cost-utility analysis. 
Fig. 1 Drawing illustrating quality-adjusted life-years gained. 1 on the vertical scales denotes perfect health and 0 dead

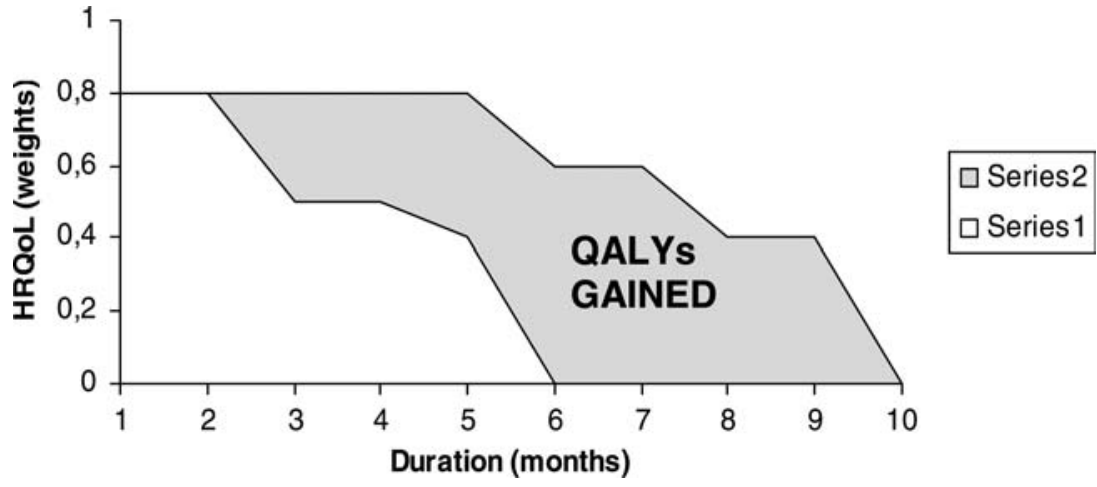

\section{EuroQol (EQ-5D)}

EuroQol was concurrently developed in five languages (Dutch, Finnish, Norwegian, Swedish and UK English) by an interdisciplinary team of European researchers (the EuroQol Group) and published in 1990 [67]. The instrument is called EQ-5D and can be obtained at the EuroQol Group homepage. ${ }^{9}$ There are official translations in many languages ${ }^{10}$ and 16 more are awaiting official status.

EQ-5D is designed for self-administration (guidelines for observer, telephone and proxy use are available) and simplicity was an important component of the design. It is intended for use in population health surveys or in combination with a condition-specific instrument for assessment to a specific condition (e.g. a spine disorder). It has good reliability and validity $[3,7,22,36,37,39$, 55] and contains five dimensions (mobility, self-care, usual activity, pain/discomfort and anxiety/depression) rated on three levels ("no problem," "some problem" or "extreme problem"). Preferences were assessed using Time Trade-off values from a subset of health states from a UK population [21]. The score ranges from 0 (death) to 1 (perfect health). In the modelling of the algorithm for the population-based tariff a factor

\footnotetext{
9 http://www.euroqol.org, accessed 2 October 2005.

${ }^{10}$ EQ-5D is currently available in Afrikaans (for South Africa), Bulgarian, Catalan, Chinese (for China, Hong Kong, Singapore, Taiwan), Croatian, Czech, Danish, Dutch (for Belgium, the Netherlands), English (for Australia, Canada, New Zealand, UK (includes Ireland), Singapore, South Africa, USA), Estonian, Finnish, French (for Belgium, France, Canada, Switzerland), German (for Germany, Austria, Switzerland), Greek, Hebrew, Hungarian, Indonesian, Italian, Japanese, Latvian, Lithuanian, Malay (for Malaysia), Norwegian, Polish, Portuguese (for Brazil, Portugal), Romanian, Russian (for Israel, Russia), Slovakian, Spanish (for Argentina, Chile, Colombia, Costa Rica, Guatemala, Mexico, Peru, Spain, Uruguay, USA, Venezuela), Slovenian, Swedish, Thai and Turkish. Source: http://www.euroqol.org/web/ users/language_a.php/, accessed 2 October 2005.
}

(interaction term called N3) of -0.269 was included if level 3 ("extreme problems") occurred within at least one dimension [21]. This results in negative scores for some health states. The EQ-5D algorithm tends to cluster scores in the upper extreme close to 1.0 and around 0.45 [6]. This was also noted in two recent clinical studies (K. A. Jansson et al., submitted for publication) [38] of lumbar disk and stenosis surgery. The second part of EQ-5D is a $20 \mathrm{~cm}$ VAS with end points labelled "Worst imaginable health state" and "Best imaginable health state."

Three types of data can be displayed [8] from EQ-5D: (a) a descriptive profile, indicating the extent of problems on each of the five dimensions, (b) a populationweighted health score, based on the descriptive data and (c) a self-rated assessment of perceived health status based on the VAS.

EuroQol is increasingly used in spine research, e.g. $[16,27,28,46,59,61,62,76]$, and also as outcome instrument in National Quality Registers of spine surgery, e.g. [38, 64, 65].

\section{SF-6D}

The SF-6D is a preference-based scoring system utilising six dimensions from SF-36, thus permitting calculations of utilities from SF-36 responses. It was developed in UK by Brazier et al. $[4,5]$ and may be obtained from the university. ${ }^{11}$

\footnotetext{
${ }^{11}$ http://www.shef.ac.uk/scharr/sections/heds/projects/sf-6d.html (accessed 14 October 2005). The SF-6D is copyrighted and is available on a license basis. A license is available free of charge for all non-commercial applications including work funded by research councils, Government agencies and charities. For commercial applications there will be a per study license (e.g. clinical trial), though an open license for a fixed period is available. The SF-6D is being used in software available from Quality Metric (www.qualitymetric.com).
} 
The eight dimensions from SF-36 were reduced to six by omitting general health perceptions and combining role limitations due to physical and emotional problems. The six dimensions included are physical functioning, role limitations, social functioning, pain, mental health and vitality, each dimension containing up to six levels generating $18,000(6 \times 4 \times 5 \times 6 \times 5 \times 5)$ unique health states. A model identified 249 health states out of the 18,000 [5].

The SF-6D preference weights were obtained from a sample of the general population using the standard gamble method [5]. Samples of the general population were asked to value the selection of health states (249), in which the model had estimated to predict all the 18,000 health states described. The SF-6D algorithm generates health state values from 1.0 (no problems of any of the six dimensions) to 0.296 (most impaired level on all six dimensions). There are floor effects reported [5, 6] indicating that SF-6D over predict poorer health states compared to EQ-5D. Good reliability and validity have been reported $[6,55]$.

Some comparisons between EQ-5D and SF-6D

Several studies compare preference-based instruments $[6,17,39,46,50,55,69]$. On average, the SF-6D generates scores that exceed EQ-5D. The difference (although statistically significant) is very small, only 0.045 . However, the two instruments generate different scores over the range of ill health, indicated by the difference in median score level where EQ-5D scores exceed the SF$6 \mathrm{D}$ values. There are ceiling effects for EQ-5D, floor effects for SF-6D and clustering effects for EQ-5D. An advantage for SF-6D is the possibility to derive the outcome in health utility from the SF-36. An advantage for EQ-5D is the huge reference data available containing health scores from normal populations, as well as different diseases, e.g. [10-14].

Minimal important difference (MID) for EQ-5D and SF-6D was reported by Walters and Frazier [70, 71]. This is an important measure for power calculations in studies. In the latter study [71], eight longitudinal investigations in 11 different patient groups that used both instruments were reviewed. The MID for EQ-5D was 0.074 and for SF-6D 0.041. The difference is probably due to the approximately double range of the EQ$5 \mathrm{D}$ scale.

\section{Influence from co-morbidity}

Co-morbidity is a factor, significantly influencing outcome in most aspects [26]. One well-known way of classifying the effect from existing co-morbidity is the American Association of Anaesthetists (ASA) score. ${ }^{12}$ The ASA score subjectively categorises patients into five subgroups by preoperative physical fitness. Since underlying fitness is an important predictor of survival from surgery, the ASA score has some correlation with outcome. As it is simple and widely understood, it is commonly used as a part of the preoperative assessment, and is an easy tool for audit.

Another score, diagnose-based rather than symptombased, was recently published [30], called the Functional Co-morbidity Index. It is based on 18 diagnoses and showed strong correlation with the SF-36 physical function subscale. The index correctly classified patients into high and low function in $77 \%$ of the cases. There is need for future studies addressing the effect of co-morbidity on HRQoL outcome.

\section{Conclusion}

There are several robust HRQoL instruments for use in spinal research. With the increased focus on healthcare resources, it is recommended that a preference-based HRQoL measure is included in the outcome so that gained QALYs can be calculated. It would be advantageous if the effect of co-morbidity on HRQoL outcome is addressed in future studies.

\footnotetext{
12 http://www.asahq.org/clinical/physicalstatus.htm, accessed 12 October 2005.
} 


\section{References}

1. Andresen EM, Fouts BS, Romeis JC, Brownson CA (1999) Performance of health-related quality-of-life instruments in a spinal cord injured population. Arch Phys Med Rehabil 80:877884

2. Bergner M, Bobbit RA, Carter WB, Gilson BS (1981) The Sickness Impact Profile: development and final revision of health status measure. Med Care 19:787-805

3. Brazier JE, Walters SJ, Nicholl JP et al (1996) Using the SF-36 and EuroQol on an elderly population. Qual Life Res 5:195-204

4. Brazier J, Usherwood T, Harper R, Thomas K (1998) Deriving a preference-based single index from the UK SF-36 Health Survey. J Clin Epidemiol 51:1115-1128

5. Brazier J, Roberts J, Deverill M (2002) The estimation of a preference-based measure of health from the SF-36. J Health Econ 21:271-292

6. Brazier J, Roberts J, Tsuchiya A, Busschbach J (2004) A comparison of the EQ-5D and SF-6D across seven patient groups. Health Econ 13:873-884

7. Brooks R (1996) EuroQol: the current state of play. Health Policy 37:53-72

8. Brooks R, Rabin R, de Charro F (eds) (2003) The measurement and valuation of health status using EQ-5D: a European perspective. Evidence from the EuroQol BIOMED Research Programme. Kluwer Academic Publishers, The Netherlands

9. Burchiel KJ, Anderson VC, Wilson BJ, Denison DB, Olson KA, Shatin D, Young RF, North RB (1995) Prognostic factors of spinal cord stimulation for chronic back and leg pain. Neurosurgery 36:1101-1111

10. Burstrom B, Fredlund P (2001) Self rated health: is it as good a predictor of subsequent mortality among adults in lower as well as in higher social classes? J Epidemiol Community Health 55:836840

11. Burstrom K, Johannesson M, Diderichsen F (2001a) Swedish population health-related quality of life results using the EQ-5D. Qual Life Res 10:621635

12. Burstrom K, Johannesson M, Diderichsen F (2001b) Health-related quality of life by disease and socio-economic group in the general population in Sweden. Health Policy 55:51-69

13. Burstrom K, Johannesson M, Diderichsen F (2003) The value of the change in health in Sweden 1980/81 to 1996/97. Health Econ 12:637-654
14. Burstrom K, Johannesson M, Diderichsen F (2005) A comparison of individual and social time trade-off values for health states in the general population. Health Policy, Oct 6, Epub ahead of print, PMID: 16214258

15. Chung YL, Mitchell HL, Houssien DA, Al-Mahrouki H, Carr AJ, Scott DL (2001) A comparative study of outcome in myositis and other musculoskeletal disorders assessed using the Nottingham Health Profile. Clin Exp Rheumatol 19:447-450

16. Cockerill W, Lunt M, Silman AJ, Cooper C, Lips P, Bhalla AK, Cannata JB, Eastell R, Felsenberg D, Gennari C, Johnell O, Kanis JA, Kiss C, Masaryk P, Naves M, Poor G, Raspe H, Reid DM, Reeve J, Stepan J, Todd C, Woolf AD, O'Neill TW (2004) Health-related quality of life and radiographic vertebral fracture. Osteoporos Int 15:113119

17. Coons SJ, Rao S, Keininger DL, Hays RD (2000) A comparative review of generic quality-of-life instruments. Pharmacoeconomics 17:13-35

18. Cortet B, Houvenagel E, Puisieux F, Roches E, Garnier P, Delcambre B (1999a) Spinal curvatures and quality of life in women with vertebral fractures secondary to osteoporosis. Spine 24:1921-1925

19. Cortet B, Cotten A, Boutry N, Flipo RM, Duquesnoy B, Chastanet P, Delcambre B (1999b) Percutaneous vertebroplasty in the treatment of osteoporotic vertebral compression fractures: an open prospective study. J Rheumatol 26:2222-2228

20. Dolan P (1996) Modelling valuations for health states: the effect of duration. Health Policy 38:189-203

21. Dolan PD (1997) Modeling valuations for EuroQol health states. Med Care 35:1095-1108

22. Dorman P, Slattery J, Farrell B, Dennis M, Sandercock P (1998) Qualitative comparison of the reliability of health status assessments with the EuroQol and SF-36 questionnaires after stroke. United Kingdom Collaborators in the International Stroke Trial. Stroke 29:63-68

23. Dursun N, Dursun E, Yalcin S (2001) Comparison of alendronate, calcitonin and calcium treatments in postmenopausal osteoporosis. Int J Clin Pract 55:505-509

24. Ettinger B, Block JE, Smith R, Cummings SR, Harris ST, Genant HK (1988) An examination of the association between vertebral deformities, physical disabilities and psychosocial problems. Maturitas 10:283-296
25. Garratt A, Schmidt L, Mackintosh A, Fitzpatrick R (2002) Quality of life measurement: bibliographic study of patient assessed health outcome measures [see comment]. Br Med J 324:1417

26. Gijsen R, Hoeymans N, Schellevis FG, Ruwaard D, Satariano WA, van den Bos GA (2001) Causes and consequences of comorbidity: a review. J Clin Epidemiol 54:661-674

27. Gilbert FJ, Grant AM, Gillan MG, Vale LD, Campbell MK, Scott NW, Knight DJ, Wardlaw D (2004a) Low back pain: influence of early MR imaging or CT on treatment and outcome-multicenter randomized trial. Radiology 231:343-351

28. Gilbert FJ, Grant AM, Gillan MG, Vale L, Scott NW, Campbell MK, Wardlaw D, Knight D, McIntosh E, Porter RW (2004b) Does early imaging influence management and improve outcome in patients with low back pain? A pragmatic randomised controlled trial. Health Technol Assess 8(iii):1-131

29. Goulet JA, Senunas LE, DeSilva GL, Greenfield M (1997) Autogenous iliac crest bone graft: complications and functional assessment. Clin Orthop Relat Res 339:76-81

30. Groll DL, To T, Bombardier C, Wright JG (2005) The development of a comorbidity index with physical function as the outcome. J Clin Epidemiol 58:595602

31. Gyrd-Hansen D (2005) Willingness to pay for a QALY: theoretical and methodological issues. Pharmacoeconomics 23:423-432

32. Hammill JM, Cook TM, Rosecrance JC (1996) Effectiveness of a physical therapy regimen in the treatment of tensiontype headache. Headache 36:149-153

33. Hidding A, Van der Linden S, Boers M, Gielen X, De Witte L, Kester A, Dijkmans B, Moolenburgh D (1993) Is group physical therapy superior to individualized therapy in ankylosing spondylitis? A randomized controlled trial. Arthritis Care Res 6:117-125

34. Hidding A, Van der Linden S, Gielen X, De Witte L, Dijkmans B, Moolenburgh D (1994) Continuation of group physical therapy is necessary in ankylosing spondylitis. Results of a randomized controlled trial. Arthritis Care Res 7:90-96

35. Hunt SM, McKenna SP, McEwen J et al (1981) The Nottingham Health Profile: subjective health status and medical consultations. Soc Sci Med $15: 221-229$ 
36. Hurst NP, Jobanputra P, Hunter M, Lambert M, Lochhead A, Brown $\mathrm{H}$ (1994) Validity of Euroqol - a generic health status instrument - in patients with rheumatoid arthritis. Economic and Health Outcomes Research Group. Br J Rheumatol 33:655-662

37. Hurst NP, Kind P, Ruta D, Hunter M, Stubbings A (1997) Measuring healthrelated quality of life in rheumatoid arthritis: validity, responsiveness and reliability of EuroQol (EQ-5D). Br J Rheumatol 36:551-559

38. Jansson KA, Németh $G$, Granath $F$, Jonsson B, Blomqvist P (2005) Healthrelated quality of life in patients before and after surgery for a herniated lumbar disc. J Bone Joint Surg Br 87:959-964

39. Johnson JA, Coons SJ (1998) Comparison of the EQ-5D and SF-12 in an adult US sample. Qual Life Res 7:155166

40. Karppinen J, Ohinmaa A, Malmivaara A, Kurunlahti M, Kyllonen E, Pienimaki T, Nieminen $\mathrm{P}$, Tervonen $\mathrm{O}$, Vanharanta H (2001) Cost effectiveness of periradicular infiltration for sciatica: subgroup analysis of a randomized controlled trial. Spine 26:25872595

41. Kendrick D, Fielding K, Bentley E, Kerslake R, Miller P, Pringle M (2001) Radiography of the lumbar spine in primary care patients with low back pain: randomised controlled trial. $\mathrm{Br}$ Med J 322(7283):400-405

42. Legroux-Gerot I, Lormeau C, Boutry N, Cotten A, Duquesnoy B, Cortet B (2004) Long-term follow-up of vertebral osteoporotic fractures treated by percutaneous vertebroplasty. Clin Rheumatol 23:310-317

43. Levy HI, Hanscom B, Boden SD (2002) Three-question depression screener used for lumbar disc herniations and spinal stenosis [see comment]. Spine 27:12321237

44. Lofgren H, Johansen F, Skogar O, Levander B (2003) Reduced pain after surgery for cervical disc protrusion/stenosis: a 2 year clinical follow-up. Disabil Rehabil 25:1033-1043

45. Lurie J (2000) A review of generic health status measures in patients with low back pain. Spine 25:31253129

46. McDonough CM, Grove MR, Tosteson TD, Lurie JD, Hilibrand AS, Tosteson AN (2005) Comparison of EQ-5D, HUI, and SF-36-derived societal health state values among spine patient outcomes research trial (SPORT) participants. Qual Life Res 14:13211332
47. McHorney CA, Ware JE Jr, Raczek AE (1993) The MOS 36-Item Short-Form Health Survey (SF-36): II Psychometric and clinical tests of validity in measuring physical and mental health constructs. Med Care 31:247-263

48. McHorney CA, Ware JE Jr, Lu JF, Sherbourne CD (1994) The MOS 36item Short-Form Health Survey (SF36): III Tests of data quality, scaling assumptions, and reliability across diverse patient groups. Med Care 32:40 66

49. Meyers AR, Andresen EM (2000) Enabling our instruments: accommodation, universal design, and access to participation in research. Arch Phys Med Rehabil 81:S5-S9

50. O'Brien BJ, Spath M, Blackhouse G, Severens JL, Dorian P, Brazier J (2003) A view from the bridge: agreement between the SF-6D utility algorithm and the Health Utilities Index. Health Econ 12:975-981

51. Ohnmeiss DD, Rashbaum RF, Bogdanffy GM, Sonntag VKH, Hurlbert RJ (1996) Prospective outcome evaluation of spinal cord stimulation in patients with intractable leg pain. Spine 21:1344-1351

52. Olson SL, O'Connor DP, Birmingham G, Broman P, Herrera L (2000) Tender point sensitivity, range of motion, and perceived disability in subjects with neck pain. J Orthop Sports Phys Ther 30:13-20

53. Papaioannou A, Adachi JD, Winegard K, Ferko N, Parkinson W, Cook RJ, Webber C, McCartney N (2003) Efficacy of home-based exercise for improving quality of life among elderly women with symptomatic osteoporosisrelated vertebral fractures. Osteoporos Int 14:677-682

54. Persson LCG, Carlsson CA, Carlsson JY, Sherk HH (1997) Long-lasting cervical radicular pain managed with surgery, physiotherapy, or a cervical collar: a prospective, randomized study. Spine 22:751-758

55. Petrou S, Hockley C (2005) An investigation into the empirical validity of the EQ-5D and SF-6D based on hypothetical preferences in a general population. Health Econ 14:1169-1189

56. Rainville J, Hartigan C, Jouve C, Martinez E (2004) The influence of intense exercise-based physical therapy program on back pain anticipated before and induced by physical activities. Spine J 4:176-183

57. Resnik L, Dobrzykowski E (2003) Guide to outcomes measurement for patients with low back pain syndromes. J Orthop Sports Phys Ther 33:307-316; discussion 317-318
58. Resnik L, Dobrykowski E (2005) Outcomes measurement for patients with low back pain. Orthop Nurs 24:14-24

59. Rivero-Arias O, Campbell H, Gray A, Fairbank J, Frost H, Wilson-MacDonald J (2005) Surgical stabilisation of the spine compared with a programme of intensive rehabilitation for the management of patients with chronic low back pain: cost utility analysis based on a randomised controlled trial. Br Med J 330:1239

60. Saraph V, Lerch C, Walochnik N, Bach CM, Krismer M, Wimmer C (2004)

Comparison of conventional versus minimally invasive extraperitoneal approach for anterior lumbar interbody fusion. Eur Spine J 13:425-431

61. van Schoor NM, Smit JH, Twisk JW, Lips P (2005) Impact of vertebral deformities, osteoarthritis, and other chronic diseases on quality of life: a population-based study. Osteoporos Int 16:749-756

62. Solberg TK, Olsen JA, Ingebrigtsen T, Hofoss D, Nygaard OP (2005) Healthrelated quality of life assessment by the EuroQol-5D can provide cost-utility data in the field of low-back surgery. Eur Spine J April 21, Epub ahead of print, PMID: 15843969

63. Spincemaille GH, Beersen N, Dekkers MA, Theuvenet PJ (2004) Neuropathic limb pain and spinal cord stimulation: results of the Dutch prospective study. Neuromodulation 7:184-192

64. Stromqvist B (2002) Evidence-based lumbar spine surgery. The role of national registration. Acta Orthop Scand Suppl 73:34-39

65. Stromqvist B, Jonsson B, Fritzell P, Hagg O, Larsson BE, Lind B (2001) The Swedish National Register for lumbar spine surgery: Swedish Society for Spinal Surgery. Acta Orthop Scand 72:99-106

66. Stucki G, Liang MH, Lipson SJ, Fossel AH, Katz JN (1994) Contribution of neuromuscular impairment to physical functional status in patients with lumbar spinal stenosis. J Rheumatol 21:1338-1343

67. The EuroQol Group (1990) EuroQol - a new facility for the measurement of health-related quality of life. The EuroQol Group. Health Policy 16:199-208

68. Thevenon A, Bonan I, Catanzariti JF, Duquesnoy B (1994) Quality of life and vertebral osteoporosis [French]. Ann Readapt Med Phys 37:89-94

69. Tosteson AN (2000) Preference-based health outcome measures in low back pain. Spine 25:3161-3166 
70. Walters SJ, Brazier JE (2003) What is the relationship between the minimally important difference and health state utility values? The case of the SF-6D. Health Qual Life Outcomes 1:4

71. Walters SJ, Brazier JE (2005) Comparison of the minimally important difference for two health state utility measures: EQ-5D and SF-6D. Qual Life Res 14:1523-1532

72. Ware JE Jr (2000) SF-36 health survey update. Spine 25:3130-3139

73. Ware JE Jr (2001) Erratum: SF-36 health survey update Spine (2000) 25 (3130-3139)). 26:2062
74. Ware JE Jr, Sherbourne CD (1992) The MOS 36-item short-form health survey (SF-36). I. Conceptual framework and item selection. Med Care 30:473-483

75. Ware J Jr, Kosinski M, Keller SD (1996) A 12-Item Short-Form Health Survey: construction of scales and preliminary tests of reliability and validity. Med Care 34:220-233

76. Yoh K, Tanaka K, Ishikawa A, Ishibashi T, Uchino Y, Sato Y, Tobinaga M, Hasegawa N, Kamae S, Yoshizawa M (2005) Health-related quality of life (HRQOL) in Japanese osteoporotic patients and its improvement by elcatonin treatment. J Bone Miner Metab 23:167-173
77. Zahavi A, Geertzen JHB, Middel B, Staal M, Rietman JS (2004) Long term effect (more than five years) of intrathecal baclofen on impairment, disability, and quality of life in patients with severe spasticity of spinal origin. J Neurol Neurosurg Psychiatry 75:1553-1557

78. Zanoli G (2005) Outcome assessment in lumbar spine surgery. Acta Orthop Suppl 76:5-47

79. Zanoli G, Stromqvist B, Padua R, Romanini E (2000) Lessons learned searching for a HRQoL instrument to assess the results of treatment in persons with lumbar disorders. Spine 25:31783185 